Letters to the Editor

\title{
Micro-solvent Extraction Method for Preconcentration. Determination of Nickel in Sea Water by Graphite Furnace Atomic Absorption Spectrometry
}

\author{
Yoshio Shijo, Tokuo Shimizu and Kaoru SAKaI \\ Department of Environmental Chemistry, Faculty of Engineering, Utsunomiya University, \\ Ishii, Utsunomiya 321
}

\begin{abstract}
Keywords Micro-solvent extraction, nickel determination, sea water, graphite furnace atomic absorption spectrometry
\end{abstract}

The solvent extraction in the preconcentration steps of the trace elements in various aqueous samples for instrumental analysis is usually carried out with $\mathrm{ml}$ levels of solvent in $100 \mathrm{ml}$ to $2000 \mathrm{ml}$ of aqueous phase. This causes a waste of both reagents and valuable original samples.

One of the limitations of micro-solvent extraction by $\mu l$ level of solvent is the difficulty in obtaining a good separation of a small volume of the organic phase from the aqueous phase. The problem has been partly resolved by the use of a solvent which melts a few degrees above room temperature. ${ }^{1-3}$ However, this method is somewhat troublesome because the mixture must be heated before extraction and cooled afterwards.

In this paper, a simple micro-solvent extraction method for the preconcentration is described. The method is based on the extraction with $100 \mu \mathrm{l}$ of solvent in a centrifuge tube, followed by centrifuging of the mixture and sucking up the organic phase into a glass tube fitted in a Teflon tube by a glass syringe. In the previous work ${ }^{4}$, a mini-pipetor instead of the glass syringe was used for sucking up the organic phase, but the technique required great skill. The proposed technique in this report, on the contrary, is more simple and easy. In addition, the extraction with less than $10 \mu \mathrm{l}$ of solvent is possible by using more miniaturized equipment in this method. The method is widely applicable to the preconcentration steps of trace elements in various samples. The preconcentration method described above has been applied for the determination of nickel concentration in sea water by graphite furnace atomic absorption spectrometry (g.f.a.a.s.).

\section{Experimental}

Reagents and apparatus

A $1000 \mu \mathrm{g} \mathrm{ml}^{-1}$ nickel solution was prepared by dissolving nickel chloride in $0.1 \mathrm{M}$ hydrochloric acid. The concentration of nickel was standardized by chelatometric titration. Working standards were prepared by suitable dilution with $0.1 \mathrm{M}$ hydrochloric acid. A $1 \%$ sodium diethyldithiocarbamate(DDTC) solution was prepared freshly in each case by dissolving DDTC in distilled-deionized water. All the other chemicals used were of analytical-reagent grade.

A Hitachi $170-50$ atomic absorption spectrometer was used in conjunction with a Hitachi GA-2B graphite furnace atomizer with argon as the inert gas. The conditions for nickel measurement were: sample injected, $10 \mu \mathrm{l}$; drying, $180^{\circ} \mathrm{C}$ for $30 \mathrm{~s}$; ashing, $950^{\circ} \mathrm{C}$ for $30 \mathrm{~s}$; atomizing, $2800^{\circ} \mathrm{C}$ for $5 \mathrm{~s}$. The spectral line at $232.0 \mathrm{~nm}$ were used for the measurement.

\section{Procedure}

Filter sea water which was acidified at $0.1 \mathrm{M}$ hydrochloric acid with a Millipore filter. Place $40 \mathrm{ml}$ of filtrate in a $60 \mathrm{ml}$ of centrifuge tube and add $1 \mathrm{ml}$ of 1 $\mathrm{M}$ citric acid. Adjust the $\mathrm{pH}$ of the solution at 8.0 with ammonia water, using a glass electrode as a test tube. Add $0.5 \mathrm{ml}$ of $1 \%$ DDTC solution, then extract the nickel-DDTC complex with $0.1 \mathrm{ml}$ of 1-chlorotoluene for $10 \mathrm{~min}$. After centrifuging at 2000 r.p.m. for $2 \mathrm{~min}$, suck up the organic phase into a glass tube fitted in a Teflon tube with a glass syringe. Transfer the organic phase in a $1 \mathrm{ml}$ of specimen bottle and measure the nickel concentration by g.f.a.a.s.

\section{Results and Discussion}

\section{Equipment for microsolvent extraction method}

The instruments used in this work are shown in Fig. 1. After extraction, the mixture of aqueous and organic phase is centrifuged and sucked up the organic phase into a glass tube fitted in a Teflon tube. Water cannot spontaneously enter the Teflon tube of less than $0.3 \mathrm{~mm}$ inside diameter, but organic solvent can easily 


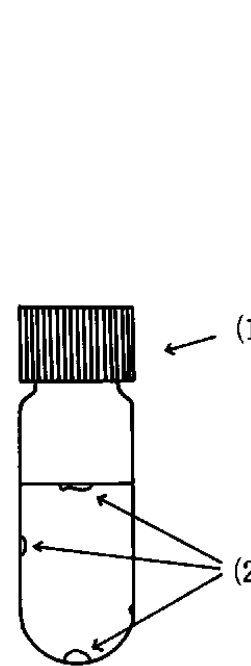

(a)

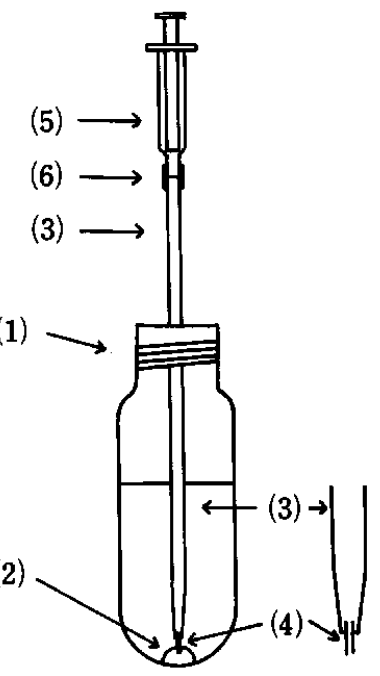

(b)
Fig. 1 Equipment for micro solvent extraction method: (a) before centrifuging, (b) after centrifuging. (1) glass centrifuge tube with Teflon lined screw cap, (2) organic phase, (3) glass tube $(4 \mathrm{~mm} \times 220 \mathrm{~mm})$, (4) tef lon tube $(0.3 \mathrm{~mm}$ i.d. $\times 5 \mathrm{~mm})$, (5) glass syringe (for tuberculin), (6) rubber tube.

Table 1 Determination of nickel in sea water

\begin{tabular}{ccc}
\hline Sample & $\begin{array}{c}\text { Nickel found/ } \\
\mu \mathrm{g} 1^{-1}\end{array}$ & $\begin{array}{c}\text { R.S.D., } \\
\%\end{array}$ \\
\hline Isozaki (east coast of Japan) & 1.68 & 7.6 \\
\hline
\end{tabular}

enter. Therefore, separation of the organic phase is carried out effectively by the proposed method.

Effects of $p H$ and of reagent concentration on the extraction
The maximum extraction of the nickel-DDTC complex from artificial sea water into 1-chlorotoluene was obtained at $\mathrm{pH} 5.5-10$ and in the DDTC concentration range above $0.5 \mathrm{mg} / 1$.

\section{Volume ratio of aqueous phase to organic phase}

Extraction of the nickel complex in various volume ratios of aqueous phase to organic phase was studied. The extract gave constant peak height on g.f.a.a.s. in the range of volume ratio $\left(V_{\mathrm{aq}} / V_{\text {org }}\right)$ at $20-800$.

\section{Analysis of sea water}

Sea water samples from the Pacific Ocean were analyzed for nickel contents by the foregoing procedure. The results are given in Table 1. It is clear that the good precision is obtained by the method proposed in this work. Further, the limit of detection of nickel in the foregoing procedure was $0.09 \mu \mathrm{g}^{-1}$.

In conclusion, the proposed method has the advantage of saving valuable samples and reagents, and of the possibility of concentrating the trace elements in not more than $1 \mathrm{ml}$ of sample solution. In addition, the extraction with less than $10 \mu \mathrm{l}$ of solvent is possible by further miniaturizing of the equipment in Fig. 1.

\section{References}

1. V. I. Kuznetsov and I. V. Seryakova, Zh. Anal. Khim., 14, 161 (1959).

2. T. Fujinaga, T. Kuwamoto and E. Nakayama, Talanta, 16, 1225 (1969).

3. H. A. Flaschka, R. Barnes and D. Paschal, Anal. Lett., 5, 253 (1972).

4. Y. Shijo, T. Shimizu, T. Saito and K. Sakai, Proceedings of 33rd Annual Meeting of The Japan Society for Analytical Chemistry, No. 1 A04 (1984).

(Received August 7, 1985) (Accepted September 30, 1985). 